\title{
Comparison of Surface Roughness When Turning and Milling
}

\author{
Abdulwahab Mgherony1*, Balázs Mikó', Gabriella Farkas \\ ${ }^{1}$ Institute of Material and Manufacturing Science, Óbuda University, H-1081 Budapest, Népszínház u. 8., Hungary \\ *Corresponding author, e-mail: mgherony.abdulwhab@uni-obuda.hu
}

Received: 25 January 2021, Accepted: 21 July 2021, Published online: 15 September 2021

\begin{abstract}
The quality of a machined surface can be described by macro and micro parameters, like the size error, the form and position error or the surface roughness. The task of machining process planning is to find the best machining method and parameters, which ensure the required quality. In this article, the surface roughness in the case of turning and milling technologies is analysed. The effect of the cutting parameters (feed at turning and depth of cut at milling) and the tool parameter (corner radius) are investigated. The results are compared with the theoretical geometric model of surface roughness. In longitudinal turning as well as in constant Z-level milling, the geometric model of surface roughness is similar. The article presents whether the real surface roughness is similar too.
\end{abstract}

\section{Keywords}

surface roughness, milling, turning, geometric model, cusp height

\section{Introduction}

Surfaces can be defined as the material boundaries. These boundaries have some intrinsic properties like colour, and other measured properties such as hardness [1]. On the other hand, the term surface texture refers to the surface geometrical form, which usually includes waviness, rough- ness and form. The surface wavelength determines the difference between these surface characteristics. In general, roughness is considered a result of the manufacturing process, it has a periodic nature, and it can produce a tool and grit marks. While, waviness is related to the machine, like irregularities in tool feed, or chatter vibrations. Form errors, on the other hand, can be caused by the absence of rigidity of the workpiece during the manufacturing process, extreme residual stress on the surface or by the strains in the workpiece material [2].

Related to the surface roughness, there are several viewpoints. The first question is, how can we define the surface roughness, and the second is how can we measure it. During the design process of a machine lot of aspects must be considered in order to define the value of the surface roughness, like the function, the tribology, the fitting, the lubrication, the look of the surface etc. The next question is how the surface can be produced considering the requirements, and the last question is how can be the surface roughness estimated based on the parameters of the production process.
Many parameters are used to describe the surface roughness based on standards, such as $\mathrm{R}_{\mathrm{t}}$ which represents the maximum depth of the roughness (Fig. 1 a)), this parameter is sometimes replaced with $R_{p}$ and $R_{v}$ which represent respectively, the height of the highest peak and the depth of the lowest valley with respect to the mean (Fig. 1 b)). $\mathrm{R}_{\mathrm{z}}$ is another parameter of surface roughness, which can be defined as the sum of the average of the five lowest valleys and the average of the five highest peaks (Fig. $1 \mathrm{c}$ )). The parameter that has a significant mathematical influence is the root mean squared $R_{q}$. $R_{a}$, on the other hand, represents the arithmetic average (Fig. $1 \mathrm{~d})$ ) [1, 3].

The stylus is one of the most common tools to measure surface $2 \mathrm{D}$ or $3 \mathrm{D}$ profiles. The three- dimensional stylus is reliable, versatile and easy to construct [4]. The main concept of work is that the vertical movement of the stylus is converted into electrical signals by a transducer. The stylus includes a pickup, which moves on the surface with constant speed. The signal of the transducer is amplified and the device records the signal [5].

The dynamic range of the transducer determines the vertical range of a stylus. Whereas, the horizontal range depends on the length of pickup traverse. Stylus dimensions determine the horizontal resolution. The main advantage of the stylus is the electrical signal output. However, there are many disadvantages, the stylus is a 


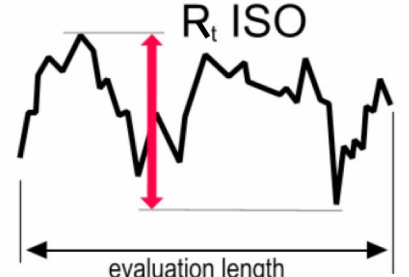

a)

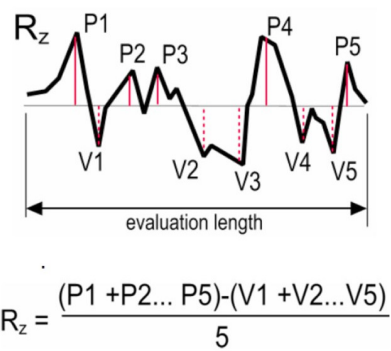

c)

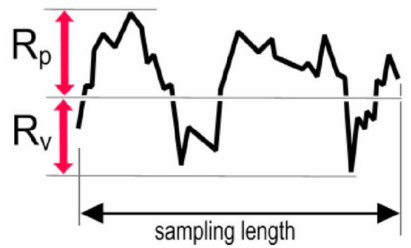

b)

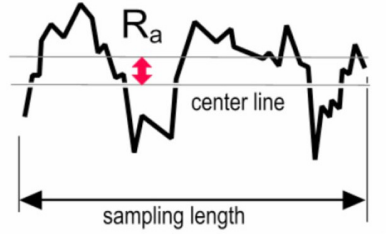

$\mathrm{R}_{\mathrm{a}}=\frac{1}{\mathrm{~L}} \int_{0}^{\mathrm{L}}|\mathrm{z}(\mathrm{x})| \mathrm{dx}$
Fig. 1 Standard surface roughness parameters; a) $R_{t}$; b) $R_{p}$ and $R_{v}$; c) $R_{z}$; d) $R_{a}$.

complex device and brittle, besides, and it is considered expensive [1].

In the industry, the quality of the produced surface is an essential factor, and it is a function of various parameters, such as the cutting conditions, the workpiece and the cutting tool, in addition to the cutting strategy. Therefore, determining the values of the process' parameters that will yield the desired product quality has a high priority among researchers.

It is possible to classify the approaches to predict surface roughness into three categories as followed in Subsections 1.1-1.3.

\subsection{Experimental approach}

In this approach, a number of factors is chosen, and several experiments are performed. The results then are analysed, and the effect of each factor and its influence on the observed character are investigated. Usually, the obtained data is used to build a model using regression analysis. This approach is used when the cause and effect relationships between the various factors do not have an analytical formulation [5].

Kovač et al. [6] built a power function based model in case of turning of stainless steel. The parameters were the cutting speed, the feed and the depth of cut. The feed das the largest effect on the surface roughness, the effect of the cutting speed and the depth of cut is very little.

Taguchi method for design of experiments (DoE) and the response surface methodology (RSM) are the most used approach to define the set of factors and levels and predict the surface roughness.

The Taguchi method contents a set of standard arrays, which determine the number of experiments that should be conducted. The number of factors and the level of these factors determine which array should be used. Using this method gives the possibility to investigate the linear effect of the factor and some interactions between the factors [5]. This approach was used by Tlhabadira et al. [7] in order to optimize the surface roughness during the milling operation. A linear regression was determined to the $\mathrm{R}_{\mathrm{a}}$ surface roughness, where the feed, the spindle speed, the depth of cut and the cutting speed were considered. Sharma and Dwivendi [8] study the effect of the specific cutting parameters on surface roughness in case of slot milling by Taguchi method. The feed rate showed the largest effect, then the spindle speed and the depth of cut.

Response surface methodology (RSM) integrates the statistical and the mathematical techniques used to develop, improve and optimize the process. It can be used to design and formulate the process. In most cases, first and second-order models are used [9].

\subsection{Artificial intelligence approach}

The development of genetic algorithm (GAs), artificial neural network (ANN), expert systems and fuzzy logic make it possible to use artificial intelligence in the predicting of surface roughness. However, ANNs and GAs are the main used methods between the researchers for this purpose [5].

Artificial neural networks are a mathematical modelling tool used to simulate any system in a way similar to the biological neural network. ANNs have the ability to define the relationship between the inputs and outputs, which made it useful to be used in engineering applications such as optimization, prediction and classification. The artificial neural networks consist of many layers of neurons [10]. Many researchers have adapted this approach. Deshpande et al. [11] used artificial neural networks to predict the surface roughness of Inconel 718 in turning based on the cutting speed, the feed and the depth of cut. Vasanth et al. [12] used ANN to predict the surface roughness of SS410 steel during hard turning.

Genetic algorithm is based on the evolution theory. It combines the principles of natural selection and natural genetics. Genetic Algorithm is suitable for solving optimization problems and obtains the optimal solution that has a high probability. The mechanism of GA is simple and starts to form a set of chromosomes. The first step in GA is 
the reproduction in this stop the good strings are selected. In the next operation, each chromosome is split, and then each one-half of a chromosome is combined with another half from a different chromosome. Then it comes to the mutation which contains flipping the chromosome. GA produces children from selected parents in a way, evolves the population toward the optimal solution. The process ends by reaching a chromosome with the best fitness criteria [13]. Li et al. [14] used genetic algorithm in order to predicting surface roughness of GH4169 in turning. The GA was used during determine the parameters of the power function of $R_{a}$.

Zhou et al. [15] investigate the turning process, where the cutting speed, the feed and the depth of cut were varied. The surface roughness prediction model was built to the measured data and use genetic-gradient boosting regression tree method. Savkovic et al. [16] present a neural network based modelling of the surface roughness of the face milling, when the cutting speed, the feed per tooth and the depth of cut are the input parameters. The input parameters were investigated in five levels. Based on the measured data a fuzzy logic and a power function model were built and compared. The neural network based model showed the best result.

\subsection{Machining theory-based approach}

In this approach, one or more aspects of machining theory are emphasized, such as cutting tool properties, process kinematics, and chip formation. Computer-aided design (CAD) methods are used to build the model that simulates the machined surface profile formation. As a result of this approach, a geometric model will be developed depending on a rigorous mathematical equation. Then a computer algorithm is used to implement this model to handle the complex calculation. In general, these modes are not accurate that is why an introduced and examined additional parameter is necessary in many cases [5].

Kundrák and Felhö [17] present the geometric modelling of the face milled surface by CAD system. The method makes possible to consider the geometric error (run-out) of the milling cutter [18]. The theoretical Ra parameter can be calculated based on the CAD model of the machined surface considering the number of teeth and the possible error. Meijer et al. [19] present an analytical geometric model of the face milled surface, consider the contour of the cutting edge and compare with the simulation based model, which consider the whole path of the cutting edge.

The aim of the article is to present the geometric model of the surface roughness in case of turning and contour milling. The article deals with the two cutting procedures based on a common theory

In this article, the surface roughness is investigated in the case of the longitudinal turning and constant Z-level milling technologies. In the case of turning, two turning tools with different corner radius were used. The effect of the feed and depth of cut were studied. The same in milling, two different cutters with different corner radius were used. The depth of cut is investigated on two levels.

Fig. 2 shows the geometric model of the cusp height $(\mathrm{CH})$, which is the base of the estimation process of surface roughness.

Based on Fig. 2 the cusp height in turning can be calculated from Eq. (1):

$$
\mathrm{RE}^{2}=\left(\frac{f}{2}\right)^{2}+(\mathrm{RE}-\mathrm{CH})^{2} .
$$

Because of the small value of $\mathrm{CH}$, the square of it is small too, so it is negligible. The cusp height is:

$$
\mathrm{CH}=\frac{f^{2}}{8 \cdot \mathrm{RE}} \text {. }
$$

Because of the similarity of the geometric model (Fig. 3), in case of Z-level milling the cusp height can be calculated in the same way:

$$
\begin{aligned}
& \mathrm{RE}^{2}=\left(\frac{a_{p}}{2 \cdot \sin A}\right)^{2}+(\mathrm{RE}-\mathrm{CH})^{2}, \\
& \mathrm{CH}=\frac{a_{p}{ }^{2}}{8 \cdot \mathrm{RE} \cdot \sin ^{2} A} .
\end{aligned}
$$

\section{Materials and method}

The work piece material used for present work was C45 (1.0503) medium-carbon unalloyed steel. The C45
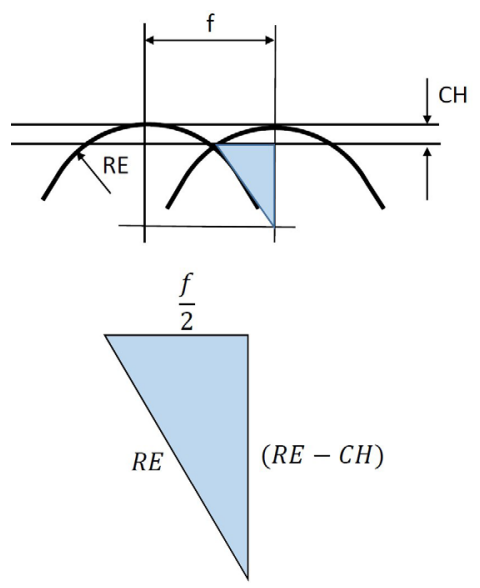

Fig. 2 Cusp height in case of a longitudinal turning. 

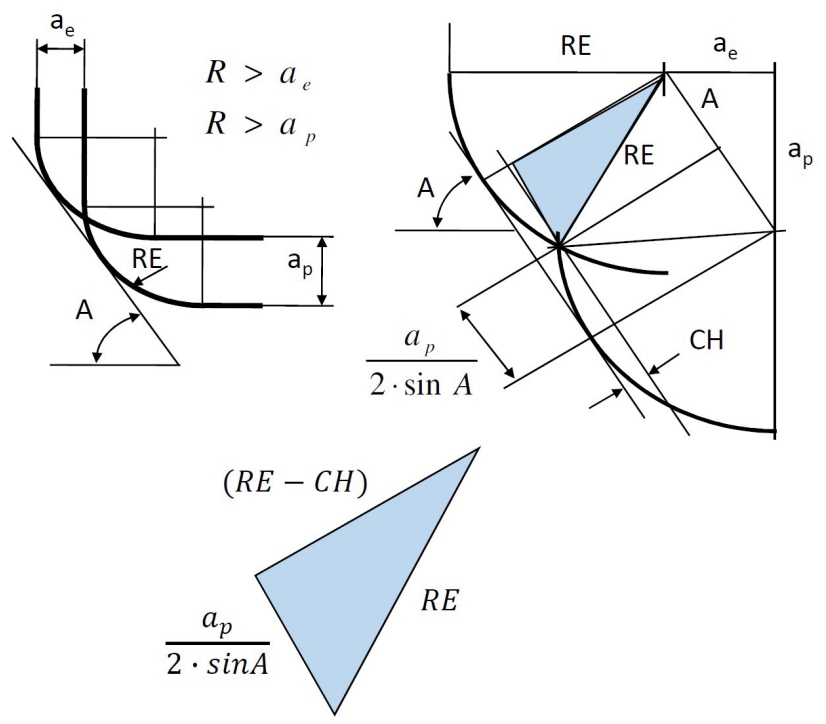

Fig. 3 Cusp height in case of the Z-level milling.

steel is used to manufacture parts with high strength requirements, such as gears, shafts, piston pins, etc., and parts that are not very stressed, such as machined parts, forgings, stampings, bolts, nuts, and pipe joints. The tensile strength is $\mathrm{R}_{\mathrm{m}}=650-800 \mathrm{MPa}$. The chemical composition of $\mathrm{C} 45$ is given in Table 1.

During the experiments turning and milling technologies were compared. The turning test parts were machined by the type E400 conventional lathe engine (tuning machine). Two different turning tools were used with different corner radius (RE): CNMG 120404-PM and CNMG 120408-PM inserts were used. The same cutting speed and three different feed were applied (Table 2).

The surface roughness was measured by the Mitutoyo SJ-301 instrument. $\mathrm{R}_{\mathrm{a}}$ and $\mathrm{R}_{\mathrm{z}}$ parameters were measured in 8 positions around the test part, and the presented values were calculated with the averages of them.

In case of milling, the test parts were machined by a Mazak 410-AII CNC machining centre. The surface inclination was $80^{\circ}$. Two different milling cutters were used with the same cutting speed $\left(\mathrm{v}_{\mathrm{c}}=160 \mathrm{~m} / \mathrm{min}\right)$, but two

Table 1 Chemical composition of C45 steel (analysis in \%)

\begin{tabular}{|c|c|c|c|c|c|c|c|c|}
\hline $\mathrm{C}$ & $\mathrm{Si}$ & Mn & \multicolumn{2}{|c|}{$\mathrm{P}$} & S & $\mathrm{Cr}$ & Mo & $\mathrm{Ni}$ \\
\hline $0.42-0.5$ & $<0.4$ & $0.5-0.8$ & \multicolumn{2}{|c|}{$<0.045$} & $<0.045$ & $<0.4$ & $<0.1$ & $<0.4$ \\
\hline & & & T1 & $\mathrm{T} 2$ & T3 & $\mathrm{T} 4$ & T5 & T6 \\
\hline \multicolumn{3}{|c|}{ Cutting speed $\mathrm{v}_{\mathrm{c}}(\mathrm{m} / \mathrm{min})$} & 100 & 100 & 100 & 100 & 100 & 100 \\
\hline \multicolumn{3}{|c|}{ Depth of cut $a_{p}(m m)$} & 1.0 & 1.0 & 1.0 & 1.5 & 1.5 & 1.5 \\
\hline \multicolumn{3}{|c|}{ Feed rate $\mathrm{f}(\mathrm{mm} / \mathrm{rev})$} & 0.1 & 0.15 & 0.2 & 0.1 & 0.15 & 0.2 \\
\hline \multicolumn{3}{|c|}{ Corner radius RE (mm) } & 0.4 & 0.4 & 0.4 & 0.8 & 0.8 & 0.8 \\
\hline
\end{tabular}

values of the depth of cut were applied (Table 3). The diameter of solid carbide milling cutters were $8 \mathrm{~mm}$, the number of teeth was 4 (type: Fraisa U45319.388 and U45319.391). The Z-level milling strategy was used, which means than the milling cutter moves only in the $x-y$ plane, and the surface is machined slice-by-slice.

The surface roughness was measured by Mitutoyo SJ-301 instrument. $\mathrm{R}_{\mathrm{a}}$ and $\mathrm{R}_{\mathrm{z}}$ parameters were measured in 3 positions, and the presented values calculated with the averages of these measures.

\section{The results}

The Table 4 contains the values of the calculated cusp height and the measured surface roughness. The measured data was analysed by three aspects:

1. the look of the profile,

2. the ratio of $R_{z} / R_{a}$ and

3. the relationship between the cusp height and the surface roughness.

\subsection{Characterization of surface roughness}

Representative surface profiles obtained in turning and milling operations performed are presented in Figs. 4 and 5 respectively.

From the practical point of view, of fundamental importance is the comparison of the maximum surface height $R_{z}$ and arithmetic mean height $\mathrm{R}_{\mathrm{a}}$, which are generally used by technologists and constructors.

Table 3 Cutting parameters in case of milling.

\begin{tabular}{lcccc}
\hline & M1 & M2 & M3 & M4 \\
\hline Cutting speed vc (m/min) & 160 & 160 & 160 & 160 \\
Depth of cut ap (mm) & 0.15 & 0.25 & 0.15 & 0.25 \\
Feed per tooth fz (mm/rev) & 0.05 & 0.05 & 0.05 & 0.05 \\
Corner radius RE (mm) & 0.5 & 0.5 & 1 & 1 \\
\hline
\end{tabular}

Table 4 Values of cusp height and the measured surface roughness.

\begin{tabular}{lccc}
\hline Part ID & $C H[\mu \mathrm{m}]$ & $\mathrm{R}_{\mathrm{a}}[\mu \mathrm{m}]$ & $\mathrm{R}_{\mathrm{z}}[\mu \mathrm{m}]$ \\
\hline T1 & 3.13 & 1.36 & 7.69 \\
T2 & 7.03 & 2.00 & 10.17 \\
T3 & 12.50 & 3.06 & 15.10 \\
T4 & 1.56 & 1.09 & 7.06 \\
T5 & 3.52 & 1.46 & 8.50 \\
T6 & 6.25 & 1.99 & 10.31 \\
M1 & 5.80 & 2.40 & 9.66 \\
M2 & 16.11 & 4.84 & 19.25 \\
M3 & 2.90 & 1.38 & 6.15 \\
M4 & 8.06 & 2.50 & 10.63 \\
\hline
\end{tabular}



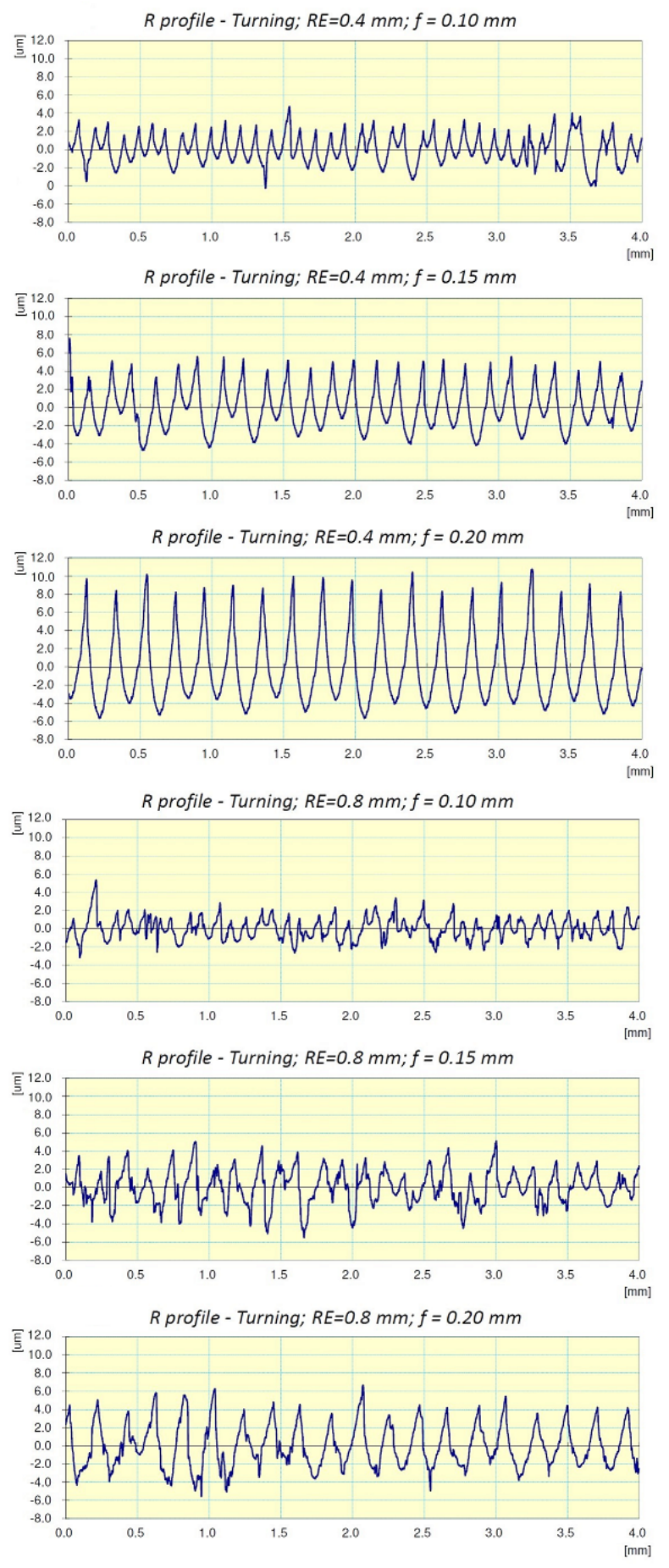

Fig. 4 Surface profiles at turning operation.

Based on Fig. 4, it can be noticed that the surface is more smooth at small feed, and the roughness increases with the increase of the feed, and that is true in both values of the depth of cut, while the ideal situation is under the smallest value of feed $f_{z}=0.1 \mathrm{~mm}$. In case of small feed the profile looks irregularly, and becomes more and more regular with the increasing feed. But in case of larger RE the profile stays irregular. The reason of this irregularity
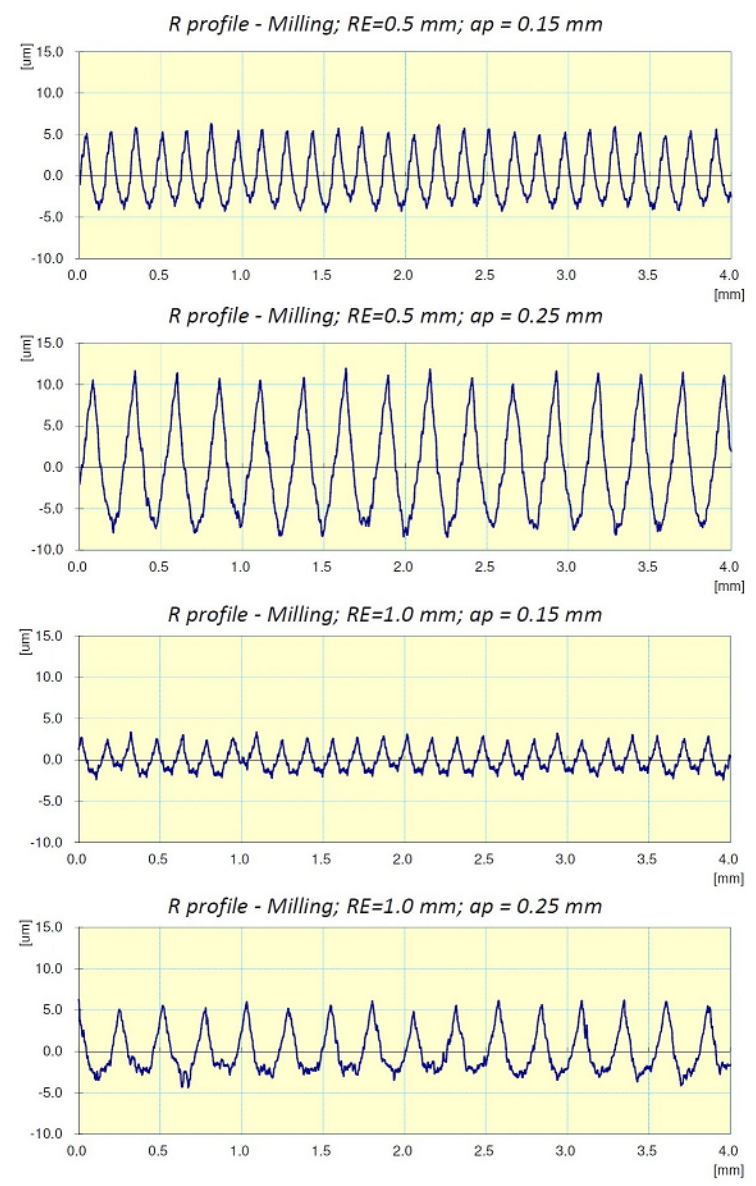

Fig. 5 Surface profiles at milling operation.

is that the surface profile is driven by not only the geometric parameters but the state of the machining environment, like the vibration and the chip removal process.

In case of milling (Fig. 5) the smoothest surface can be obtained with larger depth of cut $\left(a_{p}=0.25 \mathrm{~mm}\right)$ and larger radius corner $(\mathrm{RE}=1.0 \mathrm{~mm})$. The profiles look regular and the cusps can be recognized.

\subsection{The ratio of $R_{z} / R_{a}$}

In the machine design, the $\mathrm{R}_{\mathrm{a}}$ and $\mathrm{R}_{\mathrm{z}}$ parameters are applied too, and in case of some design steps (fitting, lubrication) the $\mathrm{R}_{\mathrm{a}}$ or the $\mathrm{R}_{\mathrm{z}}$ gets more emphasis. Therefor the conversation has large importance. But the ratio of $\mathrm{R}_{\mathrm{z}} / \mathrm{R}_{\mathrm{a}}$ is not a constant value, it depends on the production technology.

During the turning, the material of the workpiece and the cutting conditions have a significant effect on the roughness of the surface. The average value of the ratio of $\mathrm{R}_{\mathrm{z}} / \mathrm{R}_{\mathrm{a}}$ is 5.52 , the increasing $\mathrm{RE}$ increases the ratio, and the increasing feed decreases the value (Fig. 6 a)). The feed has larger effect on the ratio. 


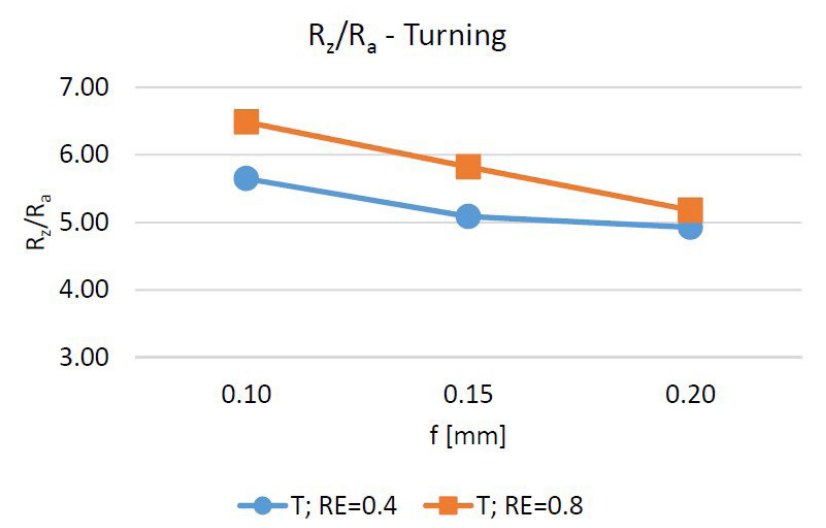

a)

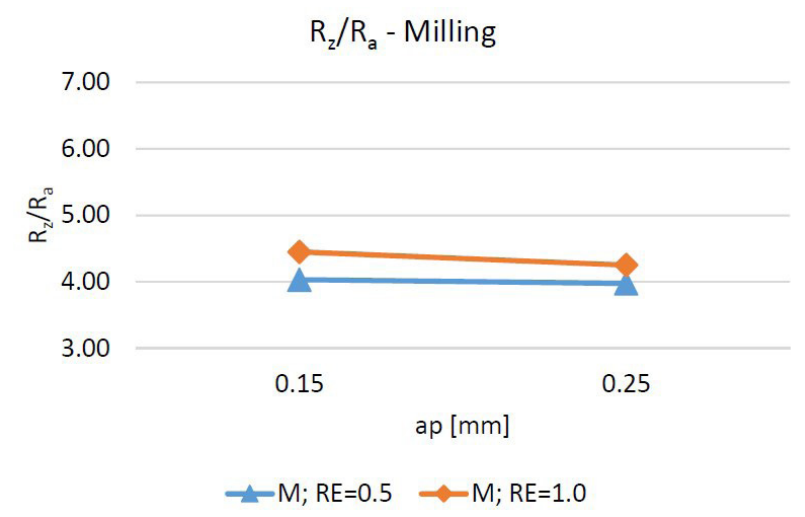

b)

Fig. 6 The ratio $\mathrm{R}_{\mathrm{z}} / \mathrm{R}_{\mathrm{a}}$; a) in the case of turning; $\mathrm{b}$ ) in the case of milling.

At the milling the average value is 4.18 , and the ratio of $\mathrm{R}_{\mathrm{z}} / \mathrm{R}_{\mathrm{a}}$ decreases with the increasing depth of cut (Fig. 6 b)). But the difference between smaller and the larger RE is smaller, than at turning. In case of smaller corner radius $(\mathrm{RE}=0.5 \mathrm{~mm})$ the change is very small.

\subsection{Comparison of cusp height and surface roughness}

Based on the machining theory based approach, there is relationship between the cusp height and the surface roughness.

Fig. 7 shows the measured surface roughness that is machined with different cutting conditions and the calculated cusp height at turning. In case of $\mathrm{R}_{\mathrm{a}}$ and $\mathrm{R}_{\mathrm{z}}$ the linear regression is work with good $\mathrm{R}^{2}$ factors $\left(\mathrm{R}_{\mathrm{Ra}}^{2}=99.62 \%\right.$; $\mathrm{R}_{\mathrm{Rz}}^{2}=98.33 \%$ ).

The relationship can be described with a linear regression:

$\mathrm{R}_{\mathrm{a}}=0.1794 \cdot \mathrm{CH}+0.8108$,

$\mathrm{R}_{\mathrm{z}}=0.7341 \cdot \mathrm{CH}+5.6444$.

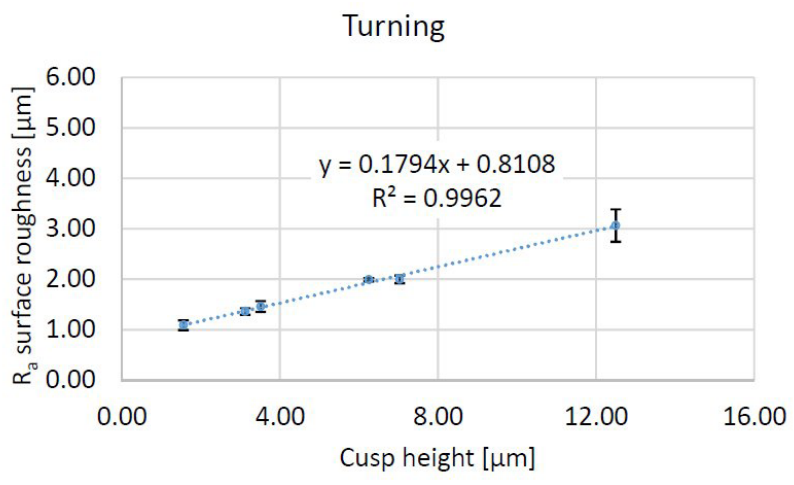

a)

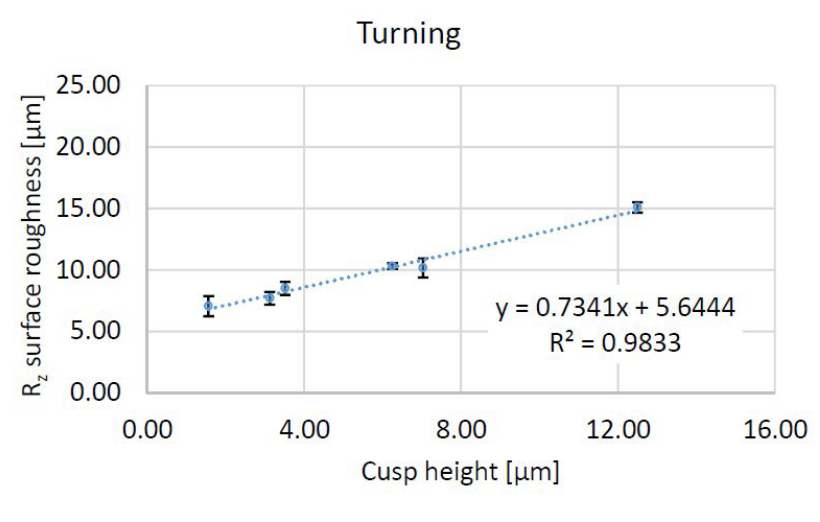

b)

Fig. 7 Measured $R_{a}$ and $R_{z}$ in function of cusp height in case of the longitudinal turning; a) $R_{a}$ surface roughness; b) $R_{z}$ surface roughness.

If the roughness of surfaces is analysed at milling method, the relationship between the cusp height and surface roughness can be described by linear regression also (Fig. 8). The $\mathrm{R}^{2}$ coefficients are very good $\left(\mathrm{R}_{\mathrm{Ra}}^{2}=98.21 \% ; \mathrm{R}_{\mathrm{Rz}}^{2}=99.15 \%\right)$, which mean a close relationship and accurate estimation.

$\mathrm{R}_{\mathrm{a}}=0.2557 \cdot \mathrm{CH}+0.6793$

$\mathrm{R}_{\mathrm{z}}=0.9762 \cdot \mathrm{CH}+3.4013$

Let's unite the measured data of the turning and milling experiments, in order to investigate the general application of the cusp height parameter. The Fig. 9 shows the regression of the united database. In case of $R_{a}$ surface roughness the regression is good $\left(\mathrm{R}_{\mathrm{Ra}}^{2}=93.66 \%\right)$, but the $\mathrm{R}_{\mathrm{z}}$ parameter can be estimated by cusp height with better accuracy. The $\mathrm{R}_{\mathrm{Rz}}^{2}$ is $96.61 \%$ and the calculated equation is:

$\mathrm{R}_{\mathrm{r}}=0.8495 \cdot \mathrm{CH}+4.7714$.

The surface roughness can be estimated based on cusp height considering the tool and cutting parameters. In the investigated case, the next form was used: 


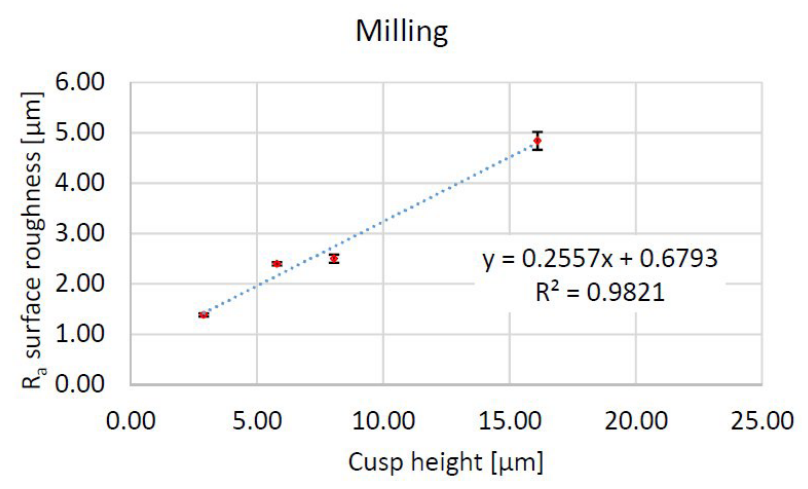

a)

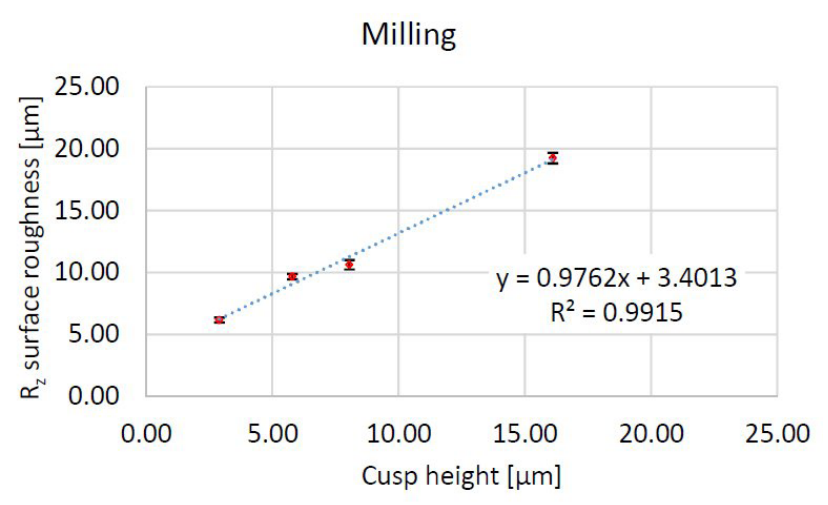

b)

Fig. 8 Measured $R_{a}$ and $R_{z}$ in fuction of cusp height in case of the Z-level milling; a) $\mathrm{R}_{\mathrm{a}}$ surface roughness; b) $\mathrm{R}_{\mathrm{z}}$ surface roughness.

$\mathrm{R}_{\mathrm{x}}=\mathrm{C}(\mathrm{RE}, \mathrm{p}) \cdot \mathrm{CH}$,

where RE is the corner radius of the tool, and the $p$ is the feed in case of turning and the depth of cut in case of contour milling.

Based on the measured data the results of the hybrid estimation approach are:

$$
\begin{aligned}
& \mathrm{R}_{\mathrm{a}}=(1.94-1.68 \cdot \mathrm{RE}+11.6 \cdot \mathrm{p}) \cdot \mathrm{CH}, \\
& \mathrm{R}_{\mathrm{z}}=(0.24-0.37 \cdot \mathrm{RE}+3.45 \cdot \mathrm{p}) \cdot \mathrm{CH} .
\end{aligned}
$$

The coefficient of determination for $\mathrm{C}(\mathrm{RE}, \mathrm{p})$ is $\mathrm{R}_{\mathrm{C}_{-} \mathrm{Ra}}^{2}=70.0 \%$ in case of $R a$ parameter and $\mathrm{R}_{\mathrm{C}_{-} \mathrm{Rz}}^{2}=88.8 \%$ in case of $\mathrm{R}_{\mathrm{z}}$ parameter.

Based on every measured data and statistical analysis, the $\mathrm{R}_{\mathrm{z}}$ parameters seems to be better for the estimation method based on cusp height.

\section{Conclusion}

This article gives a review of the importance of surface roughness, and the approaches used for predicting the surface roughness. In recent years there has been a growing

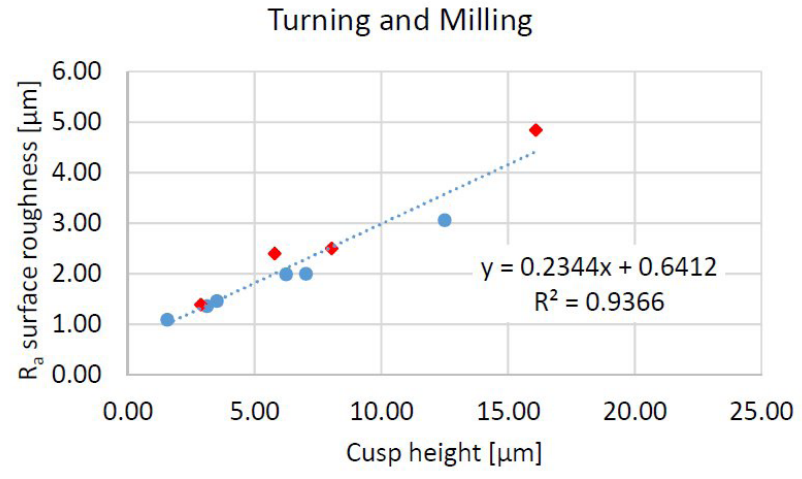

a)

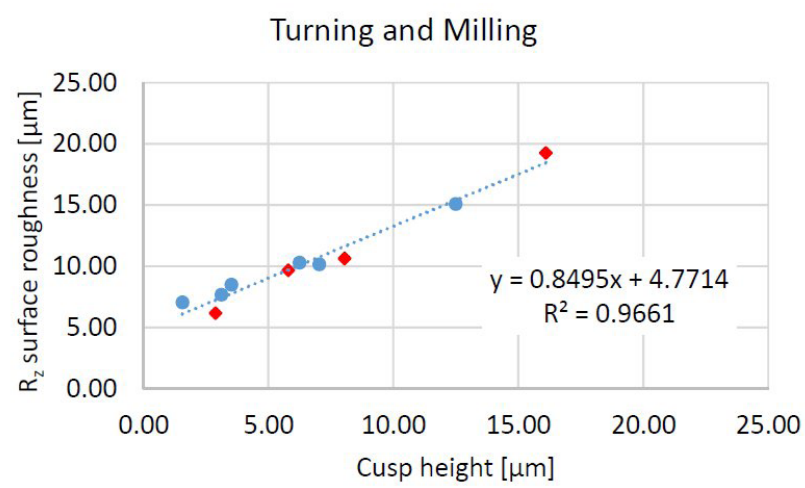

b)

Fig. 9 Cusp height values and measured surface roughness in case of the turning and milling; a) $R_{a}$ surface roughness; b) $R_{z}$ surface roughness.

interest in predicting surface roughness in order to find a more precise model despite the big number of uncontrollable factor that influences the machined surface. The cutting conditions and the cutting tool parameters have a significant impact on the surface roughness.

In this article the longitudinal turning and the Z-level milling technology were compered. In case of turning, the effect of the corner radius and the feed has been investigated. While in case of milling, the impact of corner radius and depth of cut has been studied. The presented geometric model of cusp height shows the logical equivalency of the feed of the turning and the depth of cut of the milling. The aim of the research was to present the application of the cusp height as a geometric parameter in the estimation of the surface roughness. The cusp height considers the geometric and technological parameters too.

The measured data shows, that the increasing feed of turning or the increasing depth of cut of the milling increase the surface roughness, while the increasing corner radius of the tool results decreasing surface roughness.

The calculated cusp height shows the same tendency as the measured surface roughness parameters. Though 
both of surface roughness parameters $(R z$ and $R a$ ) shows a good correlation with cusp height. But the hybrid model shown, that the Rz parameter is more suitable parameter to estimate the surface quality based on cusp height.

\section{References}

[1] Thomas, T. R. "Rough Surfaces", Imperial College Press, London, UK, 1999.

https://doi.org/10.1142/p086

[2] Blunt, L., Jiang, X. (eds.) "Advanced Techniques for Assessment Surface Topography. Development of a Basis for 3D Surface Texture Standards "Surfstand" ", Butterworth Heinemann, Oxford, UK, 2003.

https://doi.org/10.1016/B978-1-903996-11-9.X5000-2

[3] De Chiffre, L., Lonardo, P., Trumpold, H., Lucca, D. A., Goch, G., Brown, C. A., Raja, J., Hansen, H. N. "Quantitative Characterisation of Surface Texture", CIRP Annals, 49(2), pp. 635-642, 644-652, 2000 .

https://doi.org/10.1016/S0007-8506(07)63458-1

[4] Stout, K. J., Blunt, L. (eds.) "Three Dimensional Surface Topography", Butterworth Heinemann, Oxford, UK, 2000. https://doi.org/10.1016/B978-1-85718-026-8.X5112-1

[5] Benardos, P. G., Vosniakos, G. C. "Predicting surface roughness in machining: a review", International Journal of Machine Tools and Manufacture, 43(8), pp. 833-844, 2003.

https://doi.org/10.1016/S0890-6955(03)00059-2

[6] Kovač, P., Savković, B., Gostimirović, M., Jesic, D., Maňková, I. "Modelling of the Machining Surface Roughness Parameters for Steel Difficult to Machining", Analele Universitatii Eftimie Murgu Resita, 24(1), pp. 175-193, 2017.

[7] Tlhabadira, I., Daniyan, I. A., Machaka, R., Machio, C., Masu, L., VanStaden, L. R. "Modelling and optimization of surface roughness during AISI P20 milling process using Taguchi method", The International Journal of Advanced Manufacturing Technology, 102(9-12) pp. 3707-3718, 2019. https://doi.org/10.1007/s00170-019-03452-4

[8] Sharma, A., Dwivedi, V. K. "Effect of milling parameters on surface roughness: An experimental investigation", Materials Today, 25(4), pp. 868-871, 2020.

https://doi.org/10.1016/j.matpr.2019.11.256

[9] Mgherony, A. W., Mikó, B., Drégelyi-Kiss, Á. "Design of experiment in investigation regarding milling machinery", Резание и инструменты в технологических системах (Cutting \& Tooling in Technological Systems), 92, pp. 68-84, 2020. https://doi.org/10.20998/2078-7405.2020.92.09

[10] Tiryaki, S., Özşahin, Ş., Aydın, A. "Employing artificial neural networks for minimizing surface roughness and power consumption in abrasive machining of wood", European Journal of Wood and Wood Products, 75(3), pp. 347-358, 2017. https://doi.org/10.1007/s00107-016-1050-1
The results support the optimization of cutting parameters in order to produce the required surface roughness.

[11] Deshpande, Y. V., Andhare, A. B., Padole, P. M. "Application of ANN to estimate surface roughness using cutting parameters, force, sound and vibration in turning of Inconel 718", SN Applied Sciences, 1(1), Article number: 1042019.

https://doi.org/10.1007/s42452-018-0098-4

[12] Vasanth, X. A., Paul, P. S., Varadarajan, A. S. "A neural network model to predict surface roughness during turning of hardened SS410 steel", International Journal of System Assurance Engineering and Management, 11(3), pp. 704-715, 2020. https://doi.org/10.1007/s13198-020-00986-9

[13] Kumar, S. P. L. "Experimental investigations and empirical modelling for optimization of surface roughness and machining time parameters in micro end milling using Genetic Algorithm", Measurement, 124, pp. 386-394, 2018. https://doi.org/10.1016/j.measurement.2018.04.056

[14] Li, L., Wu, M., Liu, X., Cheng, Y., Yu, Y. "The prediction of surface roughness of PCBN turning GH4169 based on adaptive genetic algorithm", Integrated Ferroelectrics, 180(1), pp. 118-132, 2017.

https://doi.org/10.1080/10584587.2017.1338881

[15] Zhou, T., He, L., Wu, J., Du, F., Zou, Z. "Prediction of Surface Roughness of 304 Stainless Steel and Multi-Objective Optimization of Cutting Parameters Based on GA-GBRT", Applied Sciences, 9(18), Article number: 3684. 2019. https://doi.org/10.3390/app9183684

[16] Savkovic, B., Kovac, P., Rodic, D., Strbac, B., Klancnik, S. "Comparison of artificial neural network, fuzzy logic and genetic algorithm for cutting temperature and surface roughness prediction during the face milling process", Advances in Production Engineering \& Management, 15(2), pp. 137-150, 2020. https://doi.org/10.14743/apem2020.2.354

[17] Kundrák, J., Felhő, C. "Investigation of the Topography of Face Milled Surfaces", Materials Science Forum, 919, pp. 78-83, 2018. https://doi.org/10.4028/www.scientific.net/MSF.919.78

[18] Felhö, C., Kundrák, J. "Effects of Setting Errors (Insert RunOuts) on Surface Roughness in Face Milling When Using Circular Inserts", Machines, 6(2), Article number: 14, 2018. https://doi.org/10.3390/machines6020014

[19] Meijer, A., Bergmann, J. A., Kerbs, E., Biermann, D., Wiederkehr, P. "Analytical and Simulation-Based Prediction of Surface Roughness for Micromilling Hardened HSS", Journal of Manufacturing and Materials Processing, 3(3), Article number: 70, 2019. https://doi.org/10.3390/jmmp3030070 